\title{
Optimal Reservoir Operation for Flood Control Using Folded Dynamic Programming
}

\author{
D. Nagesh Kumar · Falguni Baliarsingh • K. Srinivasa Raju
}

Received: 7 November 2008 / Accepted: 15 July 2009 /

Published online: 25 July 2009

(C) Springer Science+Business Media B.V. 2009

\begin{abstract}
Folded Dynamic Programming (FDP) is adopted for developing optimal reservoir operation policies for flood control. It is applied to a case study of Hirakud Reservoir in Mahanadi basin, India with the objective of deriving optimal policy for flood control. The river flows down to Naraj, the head of delta where a major city is located and finally joins the Bay of Bengal. As Hirakud reservoir is on the upstream side of delta area in the basin, it plays an important role in alleviating the severity of the flood for this area. Data of 68 floods such as peaks of inflow hydrograph, peak of outflow from reservoir during each flood, peak of flow hydrograph at Naraj and $\mathrm{d} / \mathrm{s}$ catchment contribution are utilized. The combinations of 51, 54, 57 thousand cumecs as peak inflow into reservoir and 25.5, 20, 14 thousand cumecs respectively as peak $\mathrm{d} / \mathrm{s}$ catchment contribution form the critical combinations for flood situation. It is observed that the combination of 57 thousand cumecs of inflow into reservoir and 14 thousand cumecs for $\mathrm{d} / \mathrm{s}$ catchment contribution is the most critical among the critical combinations of flow series. The method proposed can be extended to similar situations for deriving reservoir operating policies for flood control.
\end{abstract}

Keywords Reservoir operation • Optimization • Folded dynamic programming • Flood routing $\cdot$ Muskingum method

\footnotetext{
D. Nagesh Kumar $(\varangle)$

Department of Civil Engineering, Indian Institute of Science, Bangalore, India e-mail: nagesh@civil.iisc.ernet.in

F. Baliarsingh

Department of Civil Engineering, CET, Bhubaneswar, India

K. Srinivasa Raju

Department of Civil Engineering, Birla Institute of Technology and Science-Pilani,

Hyderabad Campus, Hyderabad, India
} 


\section{Introduction}

Most of the living beings are affected by either too less or too much of water compared to the normal requirement. As the scarcity of water is a grave concern for management, so also the excess of it. The former situation leads to drought and the latter to flood. Both are equally alarming. Structural and non-structural measures are required to mitigate these disaster situations (Mays and Tung 1992). One of the major structural measures is construction of a dam across the river. Reservoir, created by construction of dam, can tackle both the situations, viz., drought and flood. It is natural for the beneficiaries of a reservoir to extract as much benefit as possible from a single or multi-reservoir system.

At present, most of the reservoirs are for multiple purposes. Various purposes of reservoir include irrigation, hydropower, drinking water supply, low-flow augmentation, navigation, aquaculture etc. All these purposes come under the category of conservative purpose. The management of any of the conservative purposes is similar in nature, viz., to utilize the available water of the reservoir judiciously. The reservoir, built for flood control purpose on the other hand, uses the available empty space of reservoir to absorb the flood. In the case of such flood control reservoir, it is operated for flood control and conservative purposes during some periods (for example, monsoon period in India) and is operated for only conservative purposes during rest of the year. Hence, it is more difficult to operate a multipurpose flood control reservoir than a reservoir with conservative purposes alone. Many mathematical models are developed for this purpose. But still researchers are not fully satisfied with them as new problems such as high dimensionality are coming up. This necessitated developing a new search technique, Folded Dynamic Programming (FDP) which can take care of the above difficulties to certain extent faced by earlier techniques. Keeping all the above factors in view, the main objective of the present paper is to study the applicability of Folded Dynamic Programming to a case study of Hirakud reservoir in Mahanadi basin of India for the development of long- term optimal operating policy for flood control. The paper is divided into introduction, literature review, description of Folded Dynamic Programming, description of case study, results and discussion and conclusions.

\section{Literature Review}

Reservoir operation is an important area of research in water resources for more than four decades. The various components, involved in the operation of a reservoir, are different for different systems. Yeh (1985) and Labadie (2004) have provided state-of-art reviews on optimal reservoir operation. Simonovic (1992) discussed in detail about reservoir systems analysis and explained the reasons for the gap between theory and practice. He suggested some measures to mitigate them. In this paper brief and relevant literature review is presented in the form of various themes.

\subsection{Reservoir Operation for Flood Control}

Yazicigil et al. (1983) demonstrated a real time operation model on daily basis for Green river basin with four reservoirs. The primary purpose of the reservoir system 
was flood control with recreation and low flow augmentation as secondary purposes. Kelman et al. (1989) presented a methodology for optimal design of the flood control volume for a system of eight reservoirs on the Parana river in Brazil. The objective function was to minimize the penalties associated with flood protection, i.e., the total firm energy loss. Marien et al. (1994) evolved flood control rule curves for multipurpose multireservoir system by using controllability conditions. Stochasticity of future inflows and multivariate nature of release decisions were simultaneously incorporated in evolving the rule curve. This was also applicable for more than one flood control sections and mandatory releases. This method was demonstrated on an eight-reservoir system in Brazil. Ahmad and Simonovic (2006) developed Decision Support System (DSS) to assist decision makers during different phases of flood management. The DSS is able to assist in: selecting suitable flood damage reduction options, forecasting floods, modeling the operation of flood control structures, and describing the impacts of floods in time and space. The DSS is implemented for the Red River Basin in Manitoba, Canada. Ermolieva and Sergienko (2008) considered models and approaches to the analysis and decision making under catastrophic risks. It was shown that the design of optimal robust strategies for the flood risk management can be approached as a stochastic spatially explicit optimization problem combining the goals and constraints of various stakeholders. The approach was illustrated with a case study on catastrophic flood risks and showed the importance of an appropriate combination of ex-ante and ex-post structural and financial measures. Recently Reddy and Nagesh Kumar (2006) and Nagesh Kumar and Janga Reddy (2007) have developed optimization models for reservoir operation based on evolutionary algorithms and swarm intelligence algorithms.

Al-Humoud and Esen (2006) presented two approximate methods for estimating Muskingum parameters $x$ and $K$. Computation of the slopes of the inflow and outflow hydrographs at their point of intersection, and the computation of the maximum storage within the reach is the basis for the first method, whereas computation of the inflow and outflow hydrographs at two specific points are the basis for the second method. It is concluded that out of two methods, first method gives estimates for the Muskingum parameters comparable to those of traditional estimation procedures.

Dewan et al. (2007) proposed comprehensive flood hazard management strategies for land use planning decision for the efficient management of future flood disasters in Greater Dhaka for the historical flood event of 1998 using Synthetic Aperture Radar (SAR) data with Geographical Information System (GIS) data. Machado and Ahmad (2007) assessed flood hazard caused by Atrato River in Quibdó, northwest of Colombia using statistical modeling techniques, hydraulic modeling with HECRAS and the Geographic Information System (GIS). Three flood hazard maps are generated for return periods of 10, 20 and 50 years. Saghafian et al. (2008) quantified possible effects of land use changes and identifying flood source areas for future flood control planning in the Golestan watershed located northeast of Iran.

Wei and Hsu (2008) developed a generalized multipurpose multi-reservoir optimization model based on feed-forward back-propagation neural network for basin scale flood control in which one constraint is linear channel routing. Rama Mehta and Jain (2009) developed operation policy for a multi-purpose reservoir using Neuro-Fuzzy technique for a case study of Ramganga reservoir behind Ramganga dam, Kalagarh, India. They developed three Fuzzy Rule Based (FRB) models for monsoon period and three for non monsoon period and tested. Karamouz et al. 
(2009) presented two optimization models based on GA. The first model is to determine economical combination of permanent and emergency flood control options and the second one is to determine the optimal cropping pattern.

\subsection{Dynamic Programming}

The early applications of Dynamic Programming (DP) to the reservoir problems were limited to single reservoir with single purpose only (Hall and Buras 1961; Hall 1964; Yakowitz 1982). Techniques were then extended to incorporate the multiple objectives (Hall et al. 1968). Jamieson and Wilkinson (1972) developed an automated control strategy for short-term operation of the multipurpose reservoir systems of river Dee in UK. The simulation package, DISPRIN (Dee Investigation Simulation Program for Regulating Integrated Network), was applied to the Dee river system, which has seven major sub-catchments with three reservoirs. Decisions of release from the three reservoirs were based on a dynamic programming formulation, which is an element of this package. Bras et al. (1983) used adaptive control technique for real time streamflow forecast, which was used in reservoir operation. This technique is suitable when the streamflow transition probability and system objectives are continuously updated. This was applied to High Aswan Dam at Egypt and its result was compared with those obtained by traditional steady state Stochastic Dynamic Programming (SDP) and heuristic operational policy. Yeh and Labadie (1997) applied Successive Reaching Dynamic Programming (SRDP) to minimize detention system costs of maintaining ranges of desired downstream peak flow attenuation, with basin and channel routing imbedded within the algorithm. A Multi Objective Genetic Algorithm (MOGA) was also applied to generate nondominated solutions for system cost and detention effect for a watershed-level detention system. The methodologies were applied to a layout and design of a storm water detention system in the Pazam watershed located in southern Taiwan. Teixeira and Marino (2002) developed a Forward Dynamic Programming (FDP) model to solve the problem of reservoir operation and irrigation scheduling and applied to a scenario where system of two reservoirs in parallel supplying water to three irrigation districts. Prasad et al. (2006) developed optimal irrigation planning strategies for the Nagarjuna Sagar Right Canal command in the semiarid region of South India. Deterministic Dynamic Programming (DDP) is one of the components in the modeling process. Results showed that the optimization approach can significantly improve the annual net benefit with a deficit irrigation strategy under water scarcity. Liu et al. (2006) proposed Dynamic Programming Neural-network Simplex (DPNS) model and used it to derive refill operating rules in reservoir planning and management. The model was applied to the case study of Three Gorges Reservoir (TGR).

\subsection{Improvements in Dynamic Programming to Overcome Curse of Dimensionality}

It is inferred from the available literature presented in this paper and elsewhere that DP is more widely used than any other optimization technique for complex reservoir operation. Apart from many advantages in DP, there is a major disadvantage, viz., 
'curse of dimensionality', which restricts its use for multireservoir system (high dimensionality) or when dense discritization of the state variable is needed in case of single reservoir. Most of the methods employed have two common difficulties such as requirement of initial trial trajectory to start the iteration and number of iterations required to reach the optimal solution (depends on how far the initial trajectory is from the optimal one).

Some of the variations of DP that were used for overcoming dimensionality problem/curse of dimensionality are: State increment DP (Larson 1968), Incremental DP (Hall et al. 1969), Differential DP (Jacobson and Mayne 1970), Discrete Differential DP (Heidari et al. 1971), constraint differential DP (Murray and Yakowitz 1979), progressive optimality (Turgeon 1981), and binary state DP (Ozden 1984). Perera and Codner (1998) successfully improved the computational efficiency of SDP method when applied to multiple reservoir urban water supply system. For example, In DDDP, an initial feasible trial trajectory is essential to start the process of iteration. The trial trajectory moves towards the global optimum in the grid of state increments. Trajectory may fall into local optimum, if it is in between initial trial trajectory and global one. In this regard, Bellman (1957) has suggested solving the problem with different trial trajectories. But if the dimension, i.e., number of reservoirs in the system, is large, there is no clue for the number of trial trajectories required to ensure the global optimum condition. In earlier algorithms such as DDDP, the convergence depends on the distance between initial trial trajectory and the optimal trajectory. Nagesh Kumar and Baliarsingh (2003) developed and applied Folded Dynamic Programming (FDP) to the four reservoir system proposed by Larson (1968). Unlike in earlier techniques, FDP does not start with initial trial trajectory. The iteration process is also different from others. In FDP, there is no such depending factor for convergence. It was found that FDP is performing better and computationally faster.

In the present paper, Folded Dynamic Programming is applied to a case study of Hirakud reservoir for the development of long-term optimal operating policy for flood control. Brief description of FDP is presented in the following section.

\section{Folded Dynamic Programming}

Before discussing the algorithm of FDP, it is necessary to know why word 'Folded' is prefixed to Dynamic Programming. If a flexible thread is folded twice, five folding points are obtained. These five points represent five storage states in first iteration. Length between two consecutive folding points represents state increment. Taking any consecutive three points, if the thread is again folded twice, there will be two more points making up to a total of five. Now the length between two consecutive points will be half of that of the first folding. By similar repeated folding, any point of the thread can be reached. Similarly by this folding phenomenon any value of feasible storage state from a whole range of storage states can be reached by considering a minimum of five grid points in each folding. Hence the new algorithm is named as Folded Dynamic Programming. It is also necessary to explain the way of finding maximum and minimum possible storages at the beginning of each time period, hereafter called time step, of the whole operating horizon for reservoir(s). The operating horizon, the duration of reservoir operation, is considered as stage and 
the storage of reservoir is considered as state variable in DP formulation. In physical terms, the storage state variable can be at any point between the dead storage level and full reservoir level. In the FDP algorithm, the entire storage state space at each time period is required to be divided into four equal state increments to form five grid points. The storage can be changed from any grid point of one time step to any grid point of adjacent time step. Also two types of computational procedures exists in FDP i.e., forward and backward pass. In forward pass, computations proceeds forward whereas in backward pass, computations proceed backwards. The minimum and maximum possible storages were found out by equations of forward pass, starting from initial time step with initial storage states. The possible storages of last time step were found out in the process. As these may not be the same as the desired storage states of last time step, the backward pass was carried out, starting from last time step with desired final storage state.

Step-wise procedure of the FDP algorithm is explained below.

1. Depending on the natural inflow, release capacity, and boundary conditions of storage, the minimum and maximum possible storage values for each reservoir (in case of multiple reservoir system) at every time step of operating horizon are found out.

2. Considering the minimum and maximum possible storages as two extreme grid points, three middle grid points are determined adopting uniform state increments. This means that the possible storage space at each time step is divided into four equal state increments to get five grid points. So, there are $5 M$ grid points in $M$ dimensional problem ( $M$ reservoirs in multiple reservoir system) at each time step. State increment is different for different time steps as well as for different reservoirs. The mesh of these grid points for the whole operating horizon of all the reservoirs forms the corridor.

3. Conventional DP is run through this corridor to find the trajectory, $P$, which gives maximum objective function value, $F$.

4. For finding the trajectory for next iteration, if this trajectory $(P)$ is either the minimum or maximum storage value, i.e., extreme grid points at any time step, these points are changed to the next interior grid points to form the revised trajectory. This revised trajectory will be the within the corridor for the next iteration.

5. In the next iteration, the state increment is halved at each time step. A fresh corridor is formed by taking two state increments or grid points on each side of the trajectory. Then conventional DP is run through this corridor as in step (3) to find the best trajectory, $P^{\prime}$, whose objective function value is $F^{\prime}$.

6. The iterations are continued with half value of state increments of the previous one at each time step. There can be two stopping rules. First, the decrement of state increment at a time step stops, where state increment happens to be less than a predefined value. The iteration stops, when decrement of state increment process stops at each time step. Second, the iteration stops, when $F^{\prime \prime}<\xi$ is satisfied, where $F^{\prime \prime}=\left(F^{\prime}-F\right) / F$ and $\xi$ is a predefined ratio. In the present case, second stopping rule is applied.

More details of FDP are available in Baliarsingh (2000) and Nagesh Kumar and Baliarsingh (2003). 


\section{Description of Case Study}

The case study considered, Hirakud single reservoir system is situated in Mahanadi basin. The Mahanadi basin lies mostly in Madhya Pradesh and Orissa States. It is bounded on the north by Central India Hills, on the south and east by Eastern ghats and on west by the Maikela range, the south east part of Deccan Plateau. The basin is situated between $80^{\circ} 30^{\prime}$ and $86^{\circ} 50^{\prime}$ East longitude and $19^{\circ} 20^{\prime}$ and $23^{\circ} 35^{\prime}$ North latitude. It is roughly circular in shape with a diameter of about $400 \mathrm{~km}$. with an exit passage of $160 \mathrm{~km}$ length and $60 \mathrm{~km}$ breadth. Area of this basin is 1,41,600 $\mathrm{km}^{2}$ and is broadly divisible into three distinct zones, the upper plateau, the central hill part flanked by Eastern ghats, and the delta area. Hirakud dam across Mahanadi river is located in the second zone.

Mahanadi river originates in Raipur district of Madhya Pradesh at an elevation of $442 \mathrm{~m}$ above mean sea level. The total length of this east flowing river from its origin to its outfall into the Bay of Bengal is $851 \mathrm{~km}$ of which $357 \mathrm{~km}$ is in Madhya Pradesh and remaining $494 \mathrm{~km}$ in Orissa state. After a run of $450 \mathrm{~km}$. from its starting point, the river reaches Sambalpur district of Orissa, where the Hirakud dam is built on the main river. Below the dam, the river gets water mainly from two sub-basins, Ong and $\mathrm{Tel}$, in addition to free catchment along the river. The river flows down to Naraj, the head of delta and finally joins the Bay of Bengal. The catchment area up to Naraj is $1,32,200 \mathrm{~km}^{2}$. On the $\mathrm{d} / \mathrm{s}$ of Naraj, the river divides into several branches, namely, Birupa, Chitrotpala, Devi, Kushabhadra, Bhargabi, Daya etc. and runs $80 \mathrm{~km}$. before discharging into Bay of Bengal.

The multipurpose Hirakud reservoir is utilized mainly for three purposes, flood control, irrigation, and hydropower production. There is expectation from Hirakud reservoir to control flood at coastal delta area by limiting the flow at Naraj within 25.5 thousand cumecs. There are three head regulators, which can draw 128.8 cumecs from the reservoir for irrigation purpose. Areas of 0.16 and 0.11 million hectares are irrigable from the reservoir during Kharif and Rabi seasons respectively. The total installed hydropower capacity of the project is $307.5 \mathrm{MW}$, out of which $235.5 \mathrm{MW}$ can be produced from seven units of Hirakud hydropower station, and $72 \mathrm{MW}$ from three units of Chipilima hydropower station, located further $\mathrm{d} / \mathrm{s}$ of Hirakud dam. The water, used for power generation at Hirakud, flows from Hirakud hydropower station to Chipilima hydropower station through a power channel of $22.4 \mathrm{~km}$. long. After generating power at Chipilima, water flows back into the river.

Flood control is the first preferred objective. This reservoir is situated $400 \mathrm{~km}$ upstream of confluence of Mahanadi river with the Bay of Bengal. There is no other flood controlling structure downstream of Hirakud reservoir. During monsoon season, the coastal delta part, between Naraj and Bay of Bengal, is severely affected by frequent floods. This flood prone area gets water from the Hirakud reservoir and from rainfall in the downstream catchment. Naraj is situated at the head of the delta area, where the flow of Mahanadi river is measured. The flow of Mahanadi river at Naraj is used as the indicator of occurrence of flood in the coastal delta area by the Hirakud authority. As Hirakud reservoir is on the upstream side of delta area in the basin, it plays an important role in alleviating the severity of the flood for this area. This is done by regulating release from the reservoir. Since its inception, the operating rule curves for the Hirakud reservoir are modified six times. Presently at 


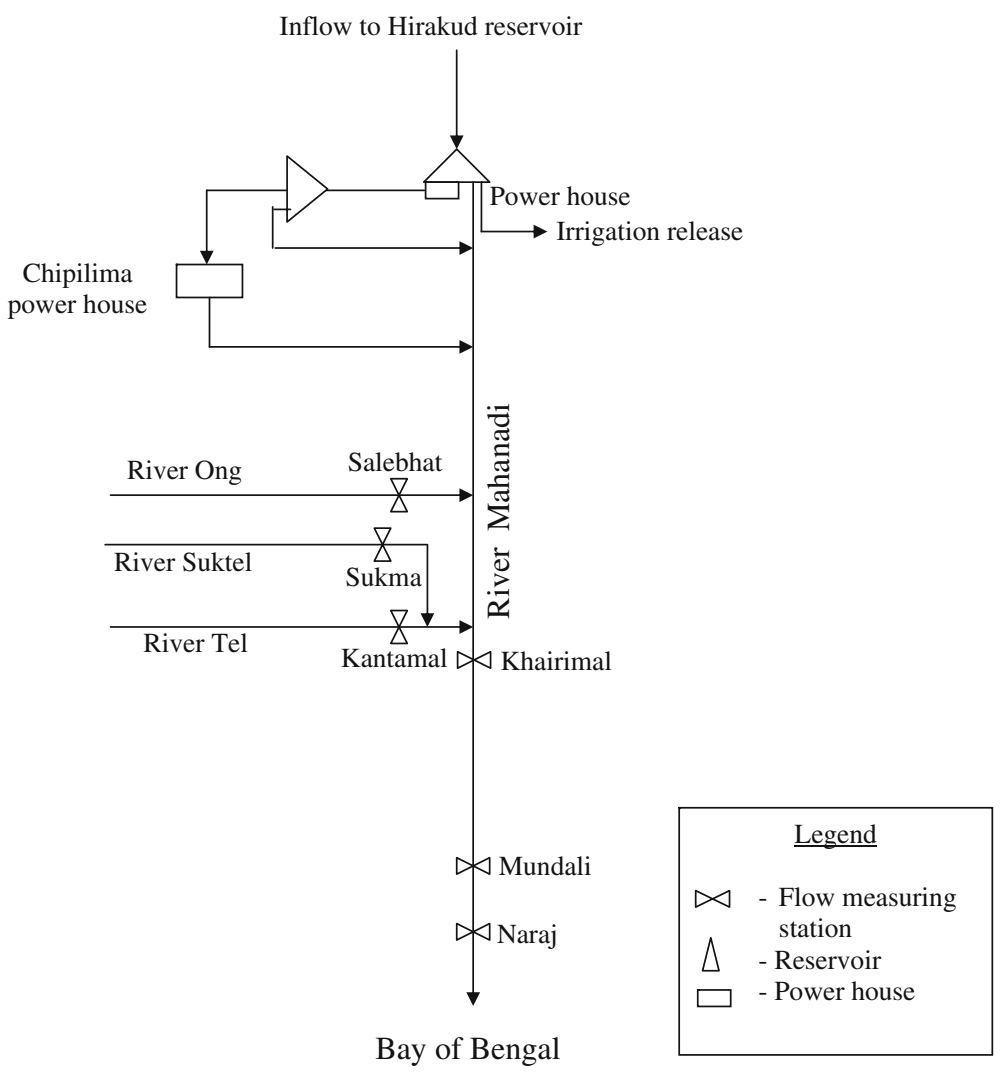

Fig. 1 Schematic diagram of Hirakud project

Hirakud reservoir, the decision of gate operation is being taken once in $12 \mathrm{~h}$ during flood. The schematic diagram of Hirakud project is shown in Fig. 1.

\section{Results and Discussion}

Various phases were formulated to derive the long-term operating policy for the reservoir. These include data collection, computation of $\mathrm{d} / \mathrm{s}$ catchment contribution, preparation of block period, application of Folded Dynamic Programming to evolve rule curves for floods. These are described below.

\subsection{Data Collection}

Data of 68 floods such as Peaks of inflow hydrograph, peak of outflow from reservoir during each flood, peak of flow hydrograph at Naraj for the period 1958 to 1995 are available in the Hirakud data book (Patri 1993). Downstream catchment contribution is not available and is estimated by the procedure as mentioned in the following sections. The outflow from the reservoir is a combination of release for 
power and spill from reservoir. The distance between the Hirakud reservoir and Naraj is $320 \mathrm{~km}$. So, apart from the measured runoff of Ong and Tel basins (Fig. 1), there is considerable amount of lateral flow coming from the free catchment between Hirakud and Naraj joining the main river, which was not measured and therefore is to be arithmetically assessed. The synthetically generated flow series (inflow into the reservoir and $\mathrm{d} / \mathrm{s}$ catchment contribution), prepared from the historical flood data of 1958-1995, are used subsequently for evolving the rule curve. These synthetically generated flow series are termed as 'representative' in the present paper.

\subsection{Computation of $\mathrm{d} / \mathrm{s}$ Catchment Contribution}

The $\mathrm{d} / \mathrm{s}$ catchment contribution during the 68 historical floods is calculated from the known values of outflow from the reservoir and flow at Naraj. The hydrograph at $\mathrm{u} / \mathrm{s}$ section of the Hirakud-Naraj river reach is the outflow of the Hirakud reservoir, which is the combination of release for power generation and spill from reservoir. This outflow collects the $\mathrm{d} / \mathrm{s}$ catchment contribution with it while travelling down to Naraj. As the $\mathrm{d} / \mathrm{s}$ catchment contribution was not measured, this data is not available for the 68 floods during 1958 and 1995. However, this quantity is calculated theoretically, by subtracting the routed quantity of outflow of Hirakud reservoir from the flow at Naraj. The relationship between the peak outflow from Hirakud reservoir and its routed quantity at Naraj is obtained from the data of nine floods between 1992 and 1995. In this regard, the reach of the river from Hirakud to Naraj is considered for application of Muskingum routing method. Muskingum equation for the flood routing is

$$
Q H_{t}=C_{0} R P S_{t-1}+C_{1} R P S_{t}+C_{2} Q H_{t-1}
$$

Where

$R P S_{t} \quad$ is the ordinate of inflow (outflow from reservoir) hydrograph at $\mathrm{u} / \mathrm{s}$ section of Hirakud-Naraj routing reach at beginning of routing interval $t$.

$\mathrm{QH}_{t} \quad$ is the ordinate of outflow (routed quantity of outflow from reservoir at Naraj) hydrograph at $\mathrm{d} / \mathrm{s}$ section of routing reach at beginning of routing interval $t$.

$C_{0}, C_{1}, C_{2}$ are the coefficients of Muskingum equation and $t$ is the routing interval.

The values of coefficients of Muskingum equation are arrived at as $C_{0}=0.471$, $C_{1}=0.117, C_{2}=0.412$. Time interval of the ordinates of the hydrographs for routing procedure is chosen as $24 \mathrm{~h}$ (Subramanya 1994). For all the nine floods considered, the initial flow at Naraj is taken to be same as the initial value of outflow from the reservoir and routing procedure is carried out to get the relationship between peak outflow from reservoir and its routed quantity at Naraj.

The percentage of attenuation varies from one flood to the other. The floods are characterized by peak outflow from reservoir. It is observed from this analysis that there is no distinct correlation between the percentage of attenuation and peak outflow from the reservoir. It is also observed that attenuation varies from a minimum of $8 \%$ to a maximum of $26 \%$ among all the floods. The higher the percentage of attenuation considered for routing, the lower would be the routed outflow quantity of Hirakud reservoir. Hence, the calculated d/s catchment contribution will be more. 
The rule curve, obtained for this higher $\mathrm{d} / \mathrm{s}$ catchment contribution will also serve for lower value of $\mathrm{d} / \mathrm{s}$ catchment contribution. So, $26 \%$ of attenuation is considered for calculation of $\mathrm{d} / \mathrm{s}$ catchment contribution, which is used for finding the representative flows. All the floods whose peak is more than 5 thousand cumecs, are taken into consideration for this purpose. By applying $26 \%$ attenuation, the peak flow at Naraj from the outflow from Hirakud reservoir alone is calculated which is assumed to occur simultaneously with the total peak flow at Naraj. This value is subtracted from the total peak flow at Naraj to get the peak flow of $\mathrm{d} / \mathrm{s}$ catchment contribution.

\subsection{Preparation of Block Period}

As the major objective of the Hirakud reservoir is flood control, the reservoir operation is considered only for the monsoon season (floods occur only in this season) in the present study. So for control purpose, reservoir is made empty at beginning of monsoon and is made full by the end of monsoon to utilize the water for conservative purposes during the following non-monsoon period. The monsoon period for reservoir operation is taken as 1st July to 30th September. The reservoir is operated for filling up from the dead storage level of $179.83 \mathrm{~m}$ on 1st July to the full reservoir level of $192.02 \mathrm{~m}$ by 1 st October every year. There are 92 days in the duration from 1st July to 30th September. Hereafter, 1st July is termed as 1st day and 30th September as 92nd day. The outflow from reservoir on 92nd day will take one more day to reach Naraj. The outflow from reservoir of 92nd day will collect

Table 1 Peaks of inflow hydrograph into the reservoir (thousand cumecs) of historical 68 floods (1958-1995) during various block periods

\begin{tabular}{|c|c|c|c|c|c|c|c|c|c|c|}
\hline \multicolumn{11}{|c|}{ Block period } \\
\hline \multirow[t]{2}{*}{$\begin{array}{l}\text { Sl. No. of } \\
\text { flood }\end{array}$} & $\begin{array}{l}1 / 7- \\
10 / 7 \\
\end{array}$ & $\begin{array}{l}11 / 7- \\
20 / 7\end{array}$ & $\begin{array}{l}21 / 7- \\
31 / 7\end{array}$ & $\begin{array}{l}1 / 8- \\
10 / 8 \\
\end{array}$ & $\begin{array}{l}11 / 8- \\
20 / 8\end{array}$ & $\begin{array}{l}21 / 8- \\
31 / 8 \\
\end{array}$ & $\begin{array}{l}1 / 9- \\
10 / 9\end{array}$ & $\begin{array}{l}11 / 9- \\
20 / 9\end{array}$ & $\begin{array}{l}21 / 9- \\
30 / 9 \\
\end{array}$ & $\begin{array}{l}\text { Non-monsoon } \\
\text { season }\end{array}$ \\
\hline & 1 & 2 & 3 & 4 & 5 & 6 & 7 & 8 & 9 & \\
\hline 1 & 43.22 & 23.83 & 14.42 & 27.49 & 23.46 & 15.73 & 25.79 & 24.43 & 16.86 & $14.4(29.10 .73)$ \\
\hline 2 & 21.54 & 23.12 & 23.83 & 7.88 & 18.42 & 29.81 & 18.82 & 19.69 & & $24.37(29.6 .86)$ \\
\hline 3 & 18.87 & 25.84 & 12.47 & 23.52 & 24.4 & 18.08 & 15.87 & 11.76 & & $20.63(21.6 .94)$ \\
\hline 4 & 18.36 & & 8.08 & 7.91 & 20.66 & 13.94 & 12.64 & 13.15 & & \\
\hline 5 & & & 15.22 & 16.18 & 18.05 & 17.82 & 17.23 & 37.75 & & \\
\hline 6 & & & 13.49 & 12.64 & 17.34 & 22.61 & & 15.3 & & \\
\hline 7 & & & 19.84 & 17.99 & 21.37 & 18.5 & & & & \\
\hline 8 & & & 15.61 & 15.3 & 16.63 & 13.43 & & & & \\
\hline 9 & & & & 15.73 & 17 & 26.92 & & & & \\
\hline 10 & & & & 14.74 & 15.98 & 13.04 & & & & \\
\hline 11 & & & & 13.29 & 19.16 & 14.74 & & & & \\
\hline 12 & & & & 17.77 & 13.21 & 14 & & & & \\
\hline 13 & & & & & & 16.58 & & & & \\
\hline 14 & & & & & & 11.82 & & & & \\
\hline $\operatorname{Max}$ & 43.22 & 25.84 & 23.83 & 27.49 & 23.46 & 29.81 & 25.79 & 37.75 & 16.86 & \\
\hline $\begin{array}{l}\text { Percent of } \\
\text { season's } \\
\text { peak }\end{array}$ & 100 & 59.8 & 55.1 & 63.6 & 54.3 & 69.0 & 59.7 & 87.3 & 39.0 & \\
\hline $\begin{array}{l}\text { No. of } \\
\text { floods }\end{array}$ & 4 & 3 & 8 & 12 & 12 & 14 & 5 & 6 & 1 & 3 \\
\hline
\end{tabular}


the $\mathrm{d} / \mathrm{s}$ catchment contribution of 93rd day to form the flow at Naraj of 93rd day. The predicted value of $\mathrm{d} / \mathrm{s}$ catchment contribution of 93rd day is to be known to take reservoir operation decision for $92 \mathrm{nd}$ day. So, the representative $\mathrm{d} / \mathrm{s}$ catchment contribution series is generated for 93 days and the representative inflow into the reservoir series is generated for 92 days. Nine blocks of 10 days each (11 in third block of July and August to accommodate last day of the month) are considered for placing one flood in each of the blocks. Although there is no chance of occurrence of flood in each of the 10 days block period simultaneously, it is assumed so, to get the rule curve, to tackle the flood during any duration individually. The peaks of inflow hydrograph to the Hirakud reservoir of the historical 68 floods are arranged in nine different block periods and are shown in Table 1 . Similarly, the peaks of calculated $\mathrm{d} / \mathrm{s}$ catchment contributions are shown in Table 2 . The peaks of individual block period with respect to the peak of the whole monsoon season in terms of percentage for both these components are also shown in Tables 1 and 2.

During transit from Bay of Bengal on to the land surface, the monsoon brings rain first to the $\mathrm{d} / \mathrm{s}$ catchment of Hirakud reservoir. Then it takes another day to travel to interior area, contributing to the inflow into the reservoir. That is why, the two representative hydrographs are made to lag by a day. The patterns of these two representative hydrographs in each block period are kept same as probable maximum flood (Patri 1993). In this process, the hydrograph of inflow into the reservoir is made to lag by a day from the hydrograph of $\mathrm{d} / \mathrm{s}$ catchment contribution.

Table 2 Peaks of calculated d/s catchment contribution (thousand cumecs) of the historical 68 floods (1958-1995) during various block periods

\begin{tabular}{|c|c|c|c|c|c|c|c|c|c|c|}
\hline \multicolumn{11}{|c|}{ Block period } \\
\hline \multirow[t]{2}{*}{$\begin{array}{l}\text { Sl. No. of } \\
\text { flood }\end{array}$} & $\begin{array}{l}1 / 7- \\
10 / 7\end{array}$ & $\begin{array}{l}11 / 7- \\
20 / 7\end{array}$ & $\begin{array}{l}21 / 7- \\
31 / 7\end{array}$ & $\begin{array}{l}1 / 8- \\
10 / 8\end{array}$ & $\begin{array}{l}11 / 8- \\
20 / 8\end{array}$ & $\begin{array}{l}21 / 8- \\
31 / 8\end{array}$ & $\begin{array}{l}1 / 9- \\
10 / 9\end{array}$ & $\begin{array}{l}11 / 9- \\
20 / 9\end{array}$ & $\begin{array}{l}21 / 9- \\
31 / 9 \\
\end{array}$ & $\begin{array}{l}\text { Non-monsoon } \\
\text { season }\end{array}$ \\
\hline & 1 & 2 & 3 & 4 & 5 & 6 & 7 & 8 & 9 & \\
\hline 1 & 14.02 & 20.23 & 19.66 & 05.38 & 02.99 & 13.38 & 24.56 & 24.95 & 07.15 & $9.69(31.10 .73)$ \\
\hline 2 & 25.53 & 13.54 & 11.08 & 16.84 & 12.26 & 13.62 & 12.73 & 23.94 & 11.27 & $18.20(29.6 .86)$ \\
\hline 3 & & 20.15 & 07.08 & 24.75 & 16.79 & 13.45 & 12.13 & 10.18 & & $11.31(22.6 .94)$ \\
\hline 4 & & 16.66 & 32.14 & 28.22 & 11.59 & 14.02 & 16.73 & 14.24 & & \\
\hline 5 & & 15.91 & 09.63 & 16.31 & 13.06 & 12.72 & 17.90 & 11.83 & & \\
\hline 6 & & & 25.20 & 17.33 & 20.55 & 10.79 & 22.50 & & & \\
\hline 7 & & & & 08.12 & 10.10 & 11.91 & & & & \\
\hline 8 & & & & 16.11 & 15.62 & 19.88 & & & & \\
\hline 9 & & & & 13.84 & 16.81 & 12.40 & & & & \\
\hline 10 & & & & 21.24 & 34.13 & 44.89 & & & & \\
\hline 11 & & & & 12.47 & 19.89 & 25.45 & & & & \\
\hline 12 & & & & 19.31 & & 05.55 & & & & \\
\hline 13 & & & & 08.68 & & 13.38 & & & & \\
\hline 14 & & & & & & 30.23 & & & & \\
\hline 15 & & & & & & 15.77 & & & & \\
\hline Max & 25.53 & 20.23 & 32.14 & 28.22 & 34.13 & 44.89 & 24.56 & 24.95 & 11.27 & \\
\hline $\begin{array}{l}\text { Percent of } \\
\text { season's } \\
\text { peak }\end{array}$ & 56.9 & 45.1 & 71.6 & 62.9 & 76.0 & 100 & 54.7 & 55.6 & 25.1 & \\
\hline $\begin{array}{l}\text { No. of } \\
\text { floods }\end{array}$ & 2 & 5 & 6 & 13 & 11 & 15 & 6 & 5 & 2 & 3 \\
\hline
\end{tabular}




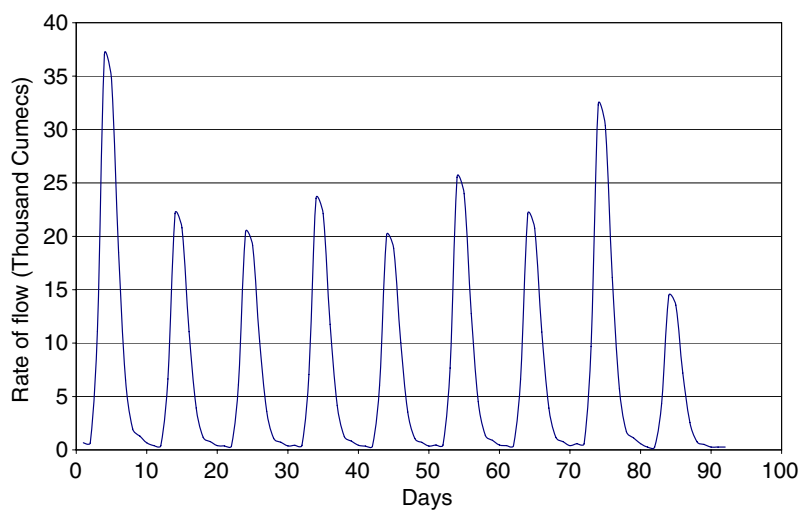

Fig. 2 Representative series of inflow into the reservoir with peak of 37 thousand cumecs

Here flow on any day means the flow at the beginning of that day. After getting the pattern of the above two series, it is necessary to obtain the flow rate of each day for various possible peaks. When the total flow reaches 9 thousand cumecs of inflow hydrograph at Naraj, it is treated as flood by the Hirakud authority. The peak of maximum probable flood into the Hirakud reservoir is 80 thousand cumecs (Patri 1993). So an operating policy is to be developed for peaks of inflow lying between 9 and 80 thousand cumecs. The various hypothetical series for inflows into the reservoir are calculated with peaks of $9,23,37,51,60,74$, and 80 thousand cumecs. Similarly, $3,9,14,20$, and 25.5 thousand cumecs of peaks of $\mathrm{d} / \mathrm{s}$ catchment contribution series are considered. Upper bound of 25.5 thousand cumecs is taken as it is required to keep the flow at Naraj below this value. It can be observed from Fig. 2 that, the data of inflow into the reservoir is generated for 92 days and the highest peak ( 37 thousand cumecs) occurs on fourth day. Similarly, the data of $\mathrm{d} / \mathrm{s}$ catchment contribution is generated for 93 days and the highest peak (25.5 thousand cumecs) occurs on 53rd day (Fig. 3).

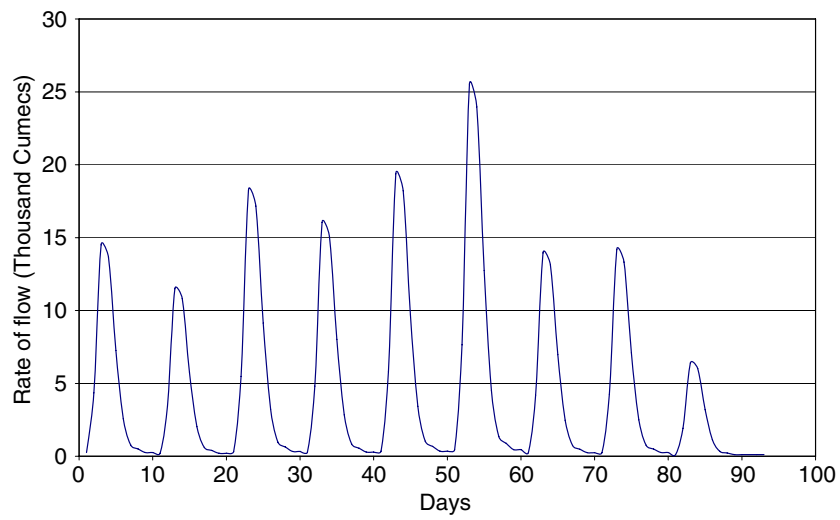

Fig. 3 Representative d/s catchment contribution series for Hirakud reservoir with peak of 25.5 thousand cumecs 


\subsection{Application of Folded Dynamic Programming to Evolve Rule Curve for Floods}

As the major objective of the Hirakud reservoir is flood control, operating policy is developed only for the monsoon season, i.e., from 1st July to 30th September. The minimum and maximum possible storages at each time step are dependent on the inflow into the reservoir, maximum release capacity during that time step and the maximum permissible release from reservoir for flood control purpose at Naraj, which varies with respect to time. The initial storage state on 1st July is taken as the dead storage and final desired storage state on 1st October is the full capacity of reservoir. So, forward pass alone is sufficient to find out the maximum possible storage state, starting from initial time step and uses the Eqs. 2, 4, 6, and 7. Backward pass alone is sufficient to find out the minimum possible storage state starting from last time step and uses Eqs. 3, 5, 6, and 7. However, both forward and backward passes were used to obtain the final values of minimum and maximum storages for each time step. In case of Hirakud reservoir system, release for power and spill from the reservoir joins back to the Mahanadi river d/s of Hirakud dam and ultimately contributes to the flow at Naraj. This quantity is to be regulated at reservoir during flood to restrict the flow at Naraj below non-damaging flow (25.5 thousand cumecs). So this factor is to be taken care of while finding minimum and maximum possible storages. Accordingly

$$
\begin{gathered}
S_{\max , t+1}=S_{\max , t}+\left(I_{t}-I R_{t}\right)-R P S_{t} \quad \forall t \\
S_{\min , t+1}=S_{\min , t}+\left(I_{t}-I R_{t}\right)-R P S_{t} \quad \forall t \\
S_{D S L} \leq S_{\max , t} \leq S_{F R L} \quad \forall t \\
S_{D S L} \leq S_{\min , t} \leq S_{F R L} \quad \forall t \\
R P S M I N \leq R P S_{t} \leq R P S M A X \quad \forall t
\end{gathered}
$$

Where
$S_{\text {max }, t}$
$S_{\text {min }, t}$
$I_{t}$
$I R_{t}$
$R P S_{t}$
$S_{D S L}$
$S_{F R L}$
RPSMIN is the minimum required release from reservoir through spillway, sluice, and powerhouse.
RPSMAX is the maximum release capacity of reservoir (Summation of maximum release through spillway, sluice, and power house).

The difference between non-damaging flow at Naraj and $\mathrm{d} / \mathrm{s}$ catchment contribution is the maximum permissible release, which can be made from reservoir to keep the flow at Naraj within non-damaging flow. For calculating the permissible release from reservoir for $t^{t h}$ day, downstream contribution of $(t+1)$ th day is considered to 
take into account the lag time between Hirakud reservoir and Naraj. It is observed in the calculations of percentage of attenuation from the historical nine floods that the percentage of attenuation varies from a minimum of $8 \%$ to a maximum of $26 \%$. If the percentage of attenuation is more than $8 \%$, then the routed quantity of flow at Naraj corresponding to outflow from reservoir will be less than the flow with $8 \%$ attenuation, without affecting the objective of filling up the reservoir. The result obtained by $8 \%$ attenuation will hold good for the flood, whose percentage of attenuation is more than this value. Therefore a minimum value of $8 \%$ attenuation is used for this purpose. The factor $1 /(1-0.08)$ is used to account for the attenuation of routing the outflow from reservoir to Naraj. $R P S_{t}$ in any period should be such an amount that the flow at Naraj will be less than non-damaging flow $(N D F)$, i. e., 25.5 thousand cumecs. Accordingly,

$$
0 \leq R P S_{t} \leq \frac{1}{1-0.08}\left(N D F-D C_{t+1}\right) \quad \forall t
$$

Where

$N D F$ is non-damaging flow at Naraj, i.e., 25.5 thousand cumecs.

$D C_{t} \quad$ is the $\mathrm{d} / \mathrm{s}$ catchment contribution during time period $t$.

The forward pass uses the Eqs. 2, 4, 6, and 7 and backward pass uses the Eqs. 3, 5, 6, and 7. Releases for irrigation and d/s catchment contribution in each time duration are the known components. Non-damaging flow at Naraj is 25.5 thousand cumecs, as adopted by Hirakud reservoir authority. Flood control objective is to try and keep the flow at Naraj, comprising release from dam with proper routing and $\mathrm{d} / \mathrm{s}$ catchment contribution, to be within 25.5 thousand cumecs (Baliarsingh 2000).

The level of $179.83 \mathrm{~m}$ [dead storage level corresponding to a volume of 1.816 Billion Cubic Meter (BCM)] of the reservoir on 1st July is expected to go to a level of $192.02 \mathrm{~m}$ (full reservoir level corresponding to a volume of 7.197 BCM) by 1 st October. So, both minimum and maximum possible storages on 1st July are 1.816 BCM. Similarly, minimum and maximum possible storages on 1st October are 7.197 BCM. For finding maximum possible storages of the remaining days of monsoon, Eqs. 2, 4, 6, and 7 are used, starting from 1st July to 1st October. For finding minimum possible storage, Eqs. 3, 5, 6, and 7 are used in backward direction, i.e., from 1st October to 1st July. The limits of release for power and spill $\left(R P S_{t}\right)$ for any time duration are given by Eqs. 6 and 7. In case of Hirakud reservoir, $R P S M I N$ is zero. So, $R P S_{t}$ can vary from a minimum value of 0 to a maximum value of $\left(N D F-D C_{t+1}\right) /(1-0.08)$ or $R P S M A X$, which ever is less. It is always tried to keep $R P S_{t}$ as 0 in Eqs. 2 and 3. Two values, minimum and maximum possible storages are different for different combinations of inflow into reservoir and $\mathrm{d} / \mathrm{s}$ catchment contribution. In the process, if the maximum possible storage is more than full reservoir level in the forward pass (Eq. 2), only then the $R P S_{t}$ is allowed to be positive. Similarly, if the minimum possible storage is less than the dead storage level in backward pass (Eq. 3), only then $R P S_{t}$ will be positive. If it is not possible to keep these two factors within the limits by utilizing the $R P S_{t}$ to its full extent, then that particular combination of inflow into the reservoir and $\mathrm{d} / \mathrm{s}$ catchment contribution cannot be handled by Hirakud reservoir to keep the flow at Naraj within nondamaging flow. When this combination of inflow into the reservoir and $\mathrm{d} / \mathrm{s}$ catchment contribution occurs, the flow at Naraj will exceed non-damaging flow. One sample of 
minimum and maximum possible storages for the entire monsoon season are shown in Table 3 corresponding to a representative inflow with peak of 37 thousand cumecs and a representative $\mathrm{d} / \mathrm{s}$ catchment contribution with a peak of 25.5 thousand cumecs.

It is observed that the combination of 51 thousand cumecs as peak inflow into reservoir and any value up to 25.5 thousand cumecs as peak $\mathrm{d} / \mathrm{s}$ catchment contribution can be handled by Hirakud reservoir, but combination of 60 thousand cumecs inflow into the reservoir and any value of $\mathrm{d} / \mathrm{s}$ catchment contribution cannot be handled. The minimum and maximum possible storages for the combination of $3,9,14,20,25.5$ thousand cumecs as peak d/s catchment contribution and 9, 23, 51 thousand cumecs as peak inflow into reservoir are computed. It is observed from the analysis that there is very little change in minimum and maximum possible storages for the variation in $\mathrm{d} / \mathrm{s}$ catchment contribution for any specified value of inflow into

Table 3 Minimum and maximum possible storages for the combination of 37 thousand cumecs as peak of inflow into the reservoir and 25.5 thousand cumecs as peak of $\mathrm{d} / \mathrm{s}$ catchment contribution

\begin{tabular}{|c|c|c|c|c|c|c|c|c|}
\hline Day & $\begin{array}{l}\text { Minimum } \\
\text { possible } \\
\text { storage }\end{array}$ & $\begin{array}{l}\text { Maximum } \\
\text { possible } \\
\text { storage }\end{array}$ & Day & $\begin{array}{l}\text { Minimum } \\
\text { possible } \\
\text { storage }\end{array}$ & $\begin{array}{l}\text { Maximum } \\
\text { possible } \\
\text { storage }\end{array}$ & Day & $\begin{array}{l}\text { Minimum } \\
\text { possible } \\
\text { storage }\end{array}$ & $\begin{array}{l}\text { Maximum } \\
\text { possible } \\
\text { storage }\end{array}$ \\
\hline & $\mathrm{BCM}$ & $\mathrm{BCM}$ & & $\mathrm{BCM}$ & $\mathrm{BCM}$ & & $\mathrm{BCM}$ & $\mathrm{BCM}$ \\
\hline 1 & 1.816 & 1.816 & 32 & 1.816 & 7.197 & 63 & 1.816 & 7.197 \\
\hline 2 & 1.816 & 1.874 & 33 & 1.816 & 7.174 & 64 & 1.816 & 7.028 \\
\hline 3 & 1.816 & 1.931 & 34 & 1.816 & 6.805 & 65 & 1.985 & 7.197 \\
\hline 4 & 1.816 & 2.890 & 35 & 2.208 & 7.197 & 66 & 1.816 & 7.197 \\
\hline 5 & 3.299 & 6.087 & 36 & 1.991 & 7.197 & 67 & 1.816 & 7.197 \\
\hline 6 & 4.151 & 7.197 & 37 & 1.816 & 7.197 & 68 & 1.816 & 7.197 \\
\hline 7 & 3.427 & 7.197 & 38 & 1.816 & 7.197 & 69 & 1.816 & 7.197 \\
\hline 8 & 1.816 & 7.197 & 39 & 1.816 & 7.197 & 70 & 1.816 & 7.197 \\
\hline 9 & 1.816 & 7.197 & 40 & 1.816 & 7.197 & 71 & 1.816 & 7.197 \\
\hline 10 & 1.816 & 7.197 & 41 & 1.816 & 7.197 & 72 & 1.816 & 6.990 \\
\hline 11 & 1.816 & 7.197 & 42 & 1.816 & 7.197 & 73 & 1.816 & 5.977 \\
\hline 12 & 1.816 & 7.197 & 43 & 1.816 & 7.109 & 74 & 1.816 & 5.671 \\
\hline 13 & 1.816 & 7.197 & 44 & 1.816 & 6.946 & 75 & 2.878 & 6.733 \\
\hline 14 & 1.816 & 7.140 & 45 & 2.067 & 7.197 & 76 & 3.342 & 7.197 \\
\hline 15 & 1.873 & 7.197 & 46 & 1.816 & 7.197 & 77 & 2.549 & 7.197 \\
\hline 16 & 1.816 & 7.197 & 47 & 1.816 & 7.197 & 78 & 3.042 & 7.197 \\
\hline 17 & 1.816 & 7.197 & 48 & 1.816 & 7.197 & 79 & 3.190 & 7.197 \\
\hline 18 & 1.816 & 7.197 & 49 & 1.816 & 7.197 & 80 & 3.288 & 7.197 \\
\hline 19 & 1.816 & 7.197 & 50 & 1.816 & 7.197 & 81 & 3.338 & 7.197 \\
\hline 20 & 1.816 & 7.197 & 51 & 1.816 & 7.165 & 82 & 3.361 & 7.197 \\
\hline 21 & 1.816 & 7.197 & 52 & 1.816 & 5.528 & 83 & 3.383 & 7.197 \\
\hline 22 & 1.816 & 7.197 & 53 & 1.856 & 5.568 & 84 & 3.757 & 7.197 \\
\hline 23 & 1.816 & 7.197 & 54 & 2.374 & 6.086 & 85 & 5.004 & 7.197 \\
\hline 24 & 1.816 & 6.973 & 55 & 3.382 & 7.094 & 86 & 6.176 & 7.197 \\
\hline 25 & 2.040 & 7.197 & 56 & 3.485 & 7.197 & 87 & 6.799 & 7.197 \\
\hline 26 & 1.816 & 7.197 & 57 & 2.320 & 7.197 & 88 & 7.020 & 7.197 \\
\hline 27 & 1.816 & 7.197 & 58 & 1.816 & 7.197 & 89 & 7.086 & 7.197 \\
\hline 28 & 1.816 & 7.197 & 59 & 1.816 & 7.197 & 90 & 7.130 & 7.197 \\
\hline 29 & 1.816 & 7.197 & 60 & 1.816 & 7.197 & 91 & 7.152 & 7.197 \\
\hline 30 & 1.816 & 7.197 & 61 & 1.816 & 7.197 & 92 & 7.175 & 7.197 \\
\hline 31 & 1.816 & 7.197 & 62 & 1.816 & 7.197 & 93 & 7.197 & 7.197 \\
\hline
\end{tabular}


the reservoir. Then the process was tried with the peak inflow into the reservoir from 51 to 60 thousand cumecs at an increment interval of 3 thousand cumecs. It is observed that the combination of 51, 54, 57 thousand cumecs as peak inflow into reservoir with $25.5,20,14$ thousand cumecs respectively as peak d/s catchment contribution can be handled by Hirakud reservoir and are considered as critical combinations for flood situation. The minimum and maximum possible storages for these three critical combinations are shown in Fig. 4. Any combination with more flow rate than these three critical combinations will either create flow at Naraj to be more than non-damaging flow or/and overflow of reservoir.

Now, FDP is applied to these critical combinations of inflow into the reservoir and $\mathrm{d} / \mathrm{s}$ catchment contribution to get rule curves for flood conditions. The process of FDP is applied with the objective function (maximization) and constraints to serve the Hirakud reservoir which are as follows.

The backward recursive relationship is

$$
\text { Maximize } \begin{aligned}
p_{t}\left(S_{t}\right) & =\underset{P R_{t} \leq P R_{c a p}}{\operatorname{Max}}\left[B_{t}\left(S_{t}, P R_{t}\right)+p_{t+1}\left(S_{t+1}\right)\right] \\
t & =0,1, \ldots, T-1
\end{aligned}
$$$$
\text { where } \quad p_{T}\left(S_{T}\right)=0
$$

subject to the following constraints.

$$
\begin{aligned}
& S_{t+1}=S_{t}+C F\left[\left(I_{t}+I_{t+1}\right) / 2-\left(I R_{t}+I R_{t+1}\right) / 2\right] \\
& -C F\left[\left(P R_{t}+P R_{t+1}\right) / 2+\left(S R_{t}+S R_{t+1}\right) / 2\right] \quad t=0,1, \ldots, T-1 \\
& B_{t}\left(S_{t}, P R_{t}\right)=\left[H_{t}\left(P R_{t}+P R_{t+1}\right)\right] /(13,800 \times 2) \quad t=0,1, \ldots, T-1
\end{aligned}
$$

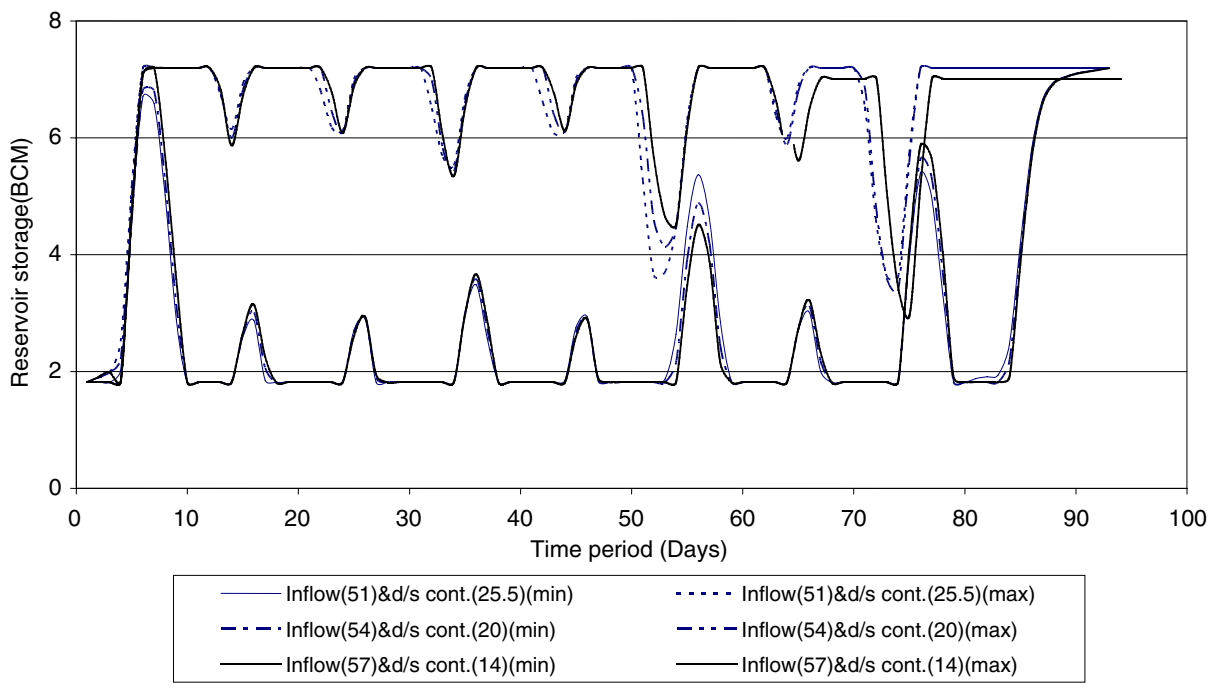

Fig. 4 Minimum and maximum possible storages for critical combinations of inflow into the reservoir and $\mathrm{d} / \mathrm{s}$ catchment contribution for flood condition 


$$
\begin{gathered}
H_{t}=f_{s}\left[\left(S_{t}+S_{t+1}\right) / 2\right] \quad t=0,1, \ldots, T-1 \\
{[1 /(1-0.08)]\left(P R_{t}+S R_{t}\right) \leq\left(N D F-D C_{t+1}\right) \quad \forall t} \\
R P S M I N \leq P R_{t}+S R_{t} \leq R P S M A X \quad \forall t \quad \forall t \\
S_{\min , t} \leq S_{t} \leq S_{\max , t} \quad \forall t \quad \forall t \\
P R_{t} \geq 0 ; S R_{t} \geq 0 \quad \forall
\end{gathered}
$$

Where
$p_{t}\left(S_{t}\right)$
is the total power produced in mega watts for the remaining periods of $t, t+1 \ldots, T-1$ with $S_{t}$ as initial storage state at the beginning of time period $t$.
$S_{t} \quad$ is the storage state in BCM at beginning of time period $t$.
$P R_{t} \quad$ is the rate of release for hydropower in cumecs (cusecs only in Eq. 11) at beginning of time period $t$.
$P R_{\text {cap }} \quad$ is the turbine capacity in cumecs.
$C F \quad$ is conversion factor to covert from rate to volume of any variable.
$I_{t} \quad$ is the rate of inflow into the reservoir in cumecs at beginning of time period $t$.
$I R_{t} \quad$ is the release rate for irrigation in cumecs at beginning of time period $t$.
$S R_{t} \quad$ is the rate of spill from dam in cumecs at beginning of time period $t$.
$B_{t}\left(S_{t}, P R_{t}\right)$ is the power produced in mega watts during time period $t$.
$H_{t} \quad$ is the average head available for power production in feet during time period $t$.
$f_{s} \quad$ is the relationship of storage-elevation curve.
$N D F \quad$ is non-damaging flow at Naraj in cumecs.
$D C_{t} \quad$ is $\mathrm{d} / \mathrm{s}$ catchment contribution at beginning of time period $t$.
RPSMIN is the minimum required release from reservoir.
RPSMAX is the maximum release capacity of reservoir.
$S_{\min , t} \quad$ is the minimum possible storage at the beginning of time period $t$.
$S_{\text {max }, t} \quad$ is the maximum possible storage at the beginning of time period $t$.

There are $T$ time periods in the operation horizon. Here $T=92$ days, in which $t$ is designated as $0,1, \ldots, 91$. In Eq. $8, p_{t}\left(S_{t}\right)$ is the objective function, which is to be maximized. Equation 9 shows the objective function value at $t=T$. This is taken as zero here, but any value other than zero will not affect the result. Mass balance of the reservoir is answered by Eq. 10. Equation 11 shows the amount of hydropower produced within time period $t$, which is a function of average release for power and the head of water available to the turbine. This equation is used by Hirakud authority, in which actual turbine efficiency is incorporated. In this equation alone, $P R_{t}$ is expressed by the unit of cusecs and $H_{t}$ by the unit of feet. The average reservoir storage level during time period $t$ can be found out from the reservoir storage by Eq. 12. This is obtained from the elevation-storage table of Hirakud reservoir (Patri 1993). The quantity released for power comes back to Mahanadi river and joins with spill and $\mathrm{d} / \mathrm{s}$ catchment contribution to make up the total flow at 
Naraj. This combined release from reservoir (release for power and spill) is restricted by Eqs. 13 and 14 taking due consideration of lag time and attenuation to keep the flow at Naraj below the non-damaging flow, i.e., 25.5 thousand cumecs. Equation 15 shows the restriction of reservoir storage state, which should be in between minimum and maximum possible storages. Equation 16 shows the non-negative constraints on release for power and spill from the dam.

As discussed earlier, the combinations of 51, 54, 57 thousand cumecs as peak inflow into reservoir and 25.5, 20, 14 thousand cumecs respectively as peak d/s catchment contribution form the critical combinations for flood situation. The rule curve for critical combination of representative series (inflow into the reservoir and $\mathrm{d} / \mathrm{s}$ catchment contribution) for flood condition is shown in Fig. 5. The continuous wave like pattern, seen in the rule curve is because of the hypothetical inflow series, where a flood is assumed during every 10 days block period. In actual flood condition, the chance of occurrence of these types of series may not be there, but there is every chance of occurrence of single flood in the corresponding 10 days block period as shown in the historical 68 floods. To make the reservoir ready to tackle these floods, the reservoir should be brought at least equal to the level corresponding to the trough of each wave. If the reservoir is at a level more than this and that particular flood occurs, either the reservoir will overflow or flow at Naraj will be more than 25.5 thousand cumecs. The final rule curve for flood condition corresponds to the trough of the waves of rule curves, obtained from the critical combination of two flow series. It may be observed in Fig. 5 that the combination of 57 thousand cumecs of inflow into reservoir and 14 thousand cumecs for $\mathrm{d} / \mathrm{s}$ catchment contribution is the most critical among the above three critical combinations of flow series. It is always necessary to keep the reservoir at the lowest level for tackling these combinations. So the rule curve, corresponding to this combination, is chosen for finding the final rule curve for flood condition. The level starts from $179.83 \mathrm{~m}$ at 0 th time period. The lowest level among all troughs of the whole season occurs in 73rd time period

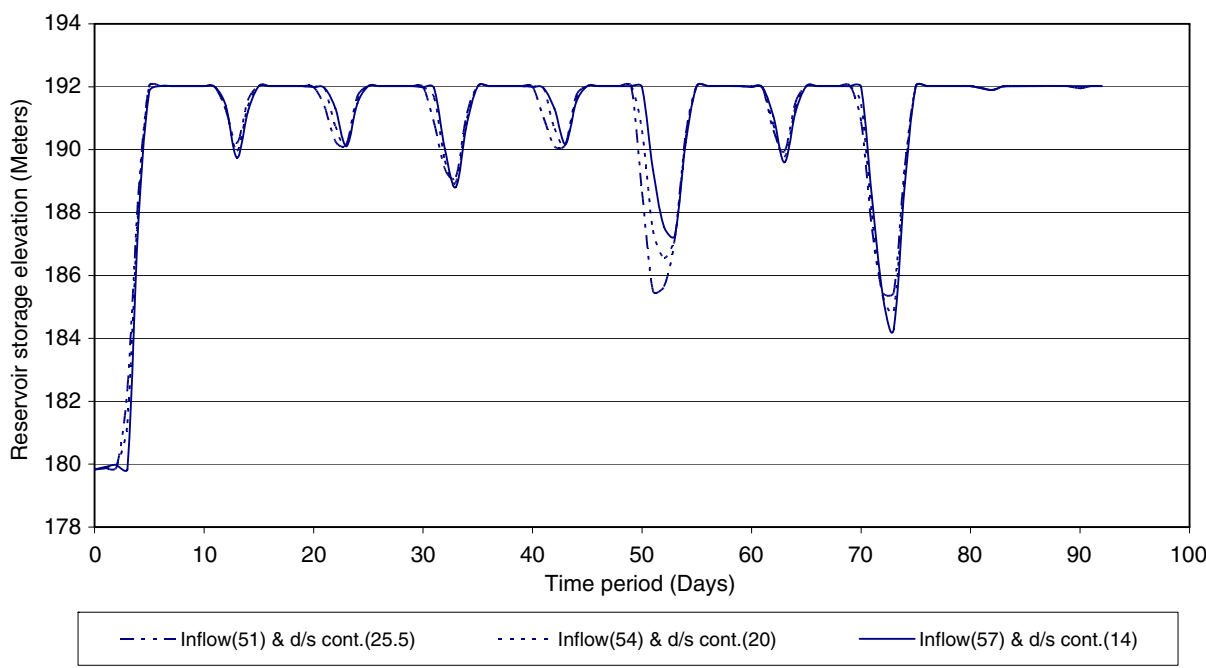

Fig. 5 Rule curve for hypothetical critical flood situation 
and corresponds to $184.3 \mathrm{~m}$. So, there is no point in increasing the level beyond $184.3 \mathrm{~m}$ before $73 \mathrm{rd}$ time period. At the end of monsoon season, i.e., at end of 92nd time period, the reservoir level is $192.02 \mathrm{~m}$. The levels for all intermediate time periods are obtained by linear interpolation. This is the final rule curve for flood condition. Although in this particular case study, only one lowest value of the troughs (corresponding to 73rd time period) is used for arriving at the final rule curve, in general case, all the troughs may have to be used if there is a gradual increase in the lowest value of troughs with increase in time. As such, this represents the most conservative attitude, which is vital for the present study area, as the main objective of reservoir is flood control.

\section{Summary and Conclusions}

In the present study, rule curve for the reservoir is evolved by a newly developed search technique of DP, which is named as Folded Dynamic Programming (FDP) for flood situations. The methodology is applied to the existing Hirakud reservoir in India, which is functioning from 1956. The flood data from 1958 to 1995 are collected to evolve the rule curve for flood situations. In this case, representative series of inflow into the reservoir and $\mathrm{d} / \mathrm{s}$ catchment contribution, whose characteristics are kept same as those of the collected historical flood data, are used. The following are the conclusions drawn from the present study.

- FDP can be applied to develop the optimal operation policy of a reservoir system for flood control.

- The long-term operating policy developed for the Hirakud reservoir system can be adopted for better utilization of the system.

- In case of need to change the operating policy due to change in hydrological regime or increased risk aversion, the methodology developed here can be used to develop a new rule curve for reservoir operation.

\section{References}

Ahmad S, Simonovic SP (2006) An intelligent decision support system for management of floods. Water Resour Manag 20:391-410

Al-Humoud JM, Esen II (2006) Approximate methods for the estimation of Muskingum flood routing parameters. Water Resour Manag 20:979-990

Baliarsingh F (2000) Long-term and short-term optimal reservoir operation for flood control. Doctoral thesis, Indian Institute of Technology, Kharagpur, India

Bellman R (1957) Dynamic programming. Princeton University Press, Princeton

Bras RL, Buchanan R, Curry KC (1983) Real time adaptive closed loop control of reservoirs with the high Aswan dam as a case study. Water Resour Res 19:33-52

Dewan AM, Islam MM, Kumamoto T, Nishigaki M (2007) Evaluating flood hazard for land-use planning in greater Dhaka of Bangladesh using remote sensing and GIS techniques. Water Resour Manag 21:1601-1612

Ermolieva TY, Sergienko IV (2008) Catastrophe risk management for sustainable development of regions under risks of natural disasters. Cybern Syst Anal 44:405-417

Hall WA (1964) Optimum design of a multipurpose reservoir. J Hydraul Div ASCE 90:141-149

Hall WA, Buras N (1961) The dynamic programming approach to water resources development. J Geophys Res 66:517-520

Hall WA, Butcher WS, Esogbue A (1968) Optimization of the operation of a multiple-purpose reservoir by dynamic programming. Water Resour Res 4:471-477 
Hall WA, Harboe R, Yeh WWG, Askew AJ (1969) Optimum firm power output from a two reservoir system by incremental dynamic programming. Contribution 130. Water Resources Center, University of California, Los Angeles

Heidari M, Chow VT, Kokotovic PV, Meredith DD (1971) Discrete differential dynamic programming approach to water resources systems optimization. Water Resour Res 7:273-282

Jacobson D, Mayne D (1970) Differential dynamic programming. Elsevier, New York

Jamieson DG, Wilkinson JC (1972) River Dee research program, 3. A short-term control strategy for multipurpose reservoir systems. Water Resour Res 8:911-920

Karamouz M, Abesi O, Moridi A, Ahmadi A (2009) Development of optimization schemes for floodplain management: a case study. Water Resour Manag 23:1743-1761

Kelman J, Damazio JM, Marien JL, Costa JPD (1989) The determination of flood control volumes in a multireservoir system. Water Resour Res 25:337-344

Labadie JW (2004) Optimal operation of multireservoir systems: state-of-the-art review. J Water Resour Plan Manage ASCE 130:93-111

Larson R (1968) State increment dynamic programming. Elsevier, New York

Liu P, Guo S, Xiong L, Li W, Zhang H (2006) Deriving reservoir refill operating rules by using the proposed DPNS model. Water Resour Manag 20:337-357

Machado SM, Ahmad S (2007) Flood hazard assessment of Atrato River in Colombia. Water Resour Manag 21:591-609

Marien JL, Damázio JM, Costa FS (1994) Building flood control rule curves for multipurpose multireservoir systems using controllability conditions. Water Resour Res 30(4):1135-1144

Mays LW, Tung YK (1992) Hydrosystems engineering and management. McGraw-Hill, Singapore

Murray DM, Yakowitz SJ (1979) Constrained differential dynamic programming and its application to multireservoir control. Water Resour Res 15:1017-1027

Nagesh Kumar D, Baliarsingh F (2003) Folded dynamic programming for optimal operation of multireservoir system. Water Resour Manag 17:337-353

Nagesh Kumar D, Janga Reddy M (2007) Multipurpose reservoir operation using particle swarm optimization. J Water Resour Plan Manage ASCE 133:192-201

Ozden M (1984) A binary state DP algorithm for operation problems of multireservoir systems. Water Resour Res 20:9-14

Patri S (1993) Data on flood control operation of Hirakud dam. Irrigation Department, Government of Orissa, India

Perera BJC, Codner GP (1998) Computational improvement for stochastic dynamic programming models of urban water supply reservoirs. J Am Water Resour Assoc 34:267-278

Prasad AS, Umamahesh NV, Viswanath GK (2006) Optimal irrigation planning under water scarcity. J Irrig Drain Eng ASCE 132:228-237

Rama Mehta, Jain SK (2009) Optimal operation of a multi-purpose reservoir using neuro-fuzzy technique. Water Resour Manag 23:509-529

Reddy MJ, Nagesh Kumar D (2006) Optimal reservoir operation using multi-objective evolutionary algorithm. Water Resour Manag 20:861-878

Saghafian B, Farazjoo H, Bozorgy B, Yazdandoost F (2008) Flood intensification due to changes in land use. Water Resour Manag 22:1051-1067

Simonovic SP (1992) Reservoir systems analysis: closing gap between theory and practice. J Water Resour Plan Manage ASCE 118:262-280

Subramanya K (1994) Engineering hydrology. McGraw-Hill, New Delhi, India

Teixeira ADS, Marino MA (2002) Coupled reservoir operation-irrigation scheduling by dynamic programming. J Irrig Drain Eng ASCE 128:63-73

Turgeon A (1981) Optimal short-term hydro scheduling from the principle of progressive optimality. Water Resour Res 17:481-486

Wei CC, Hsu NS (2008) Multireservoir flood-control optimization with neural-based linear channel level routing under tidal effects. Water Resour Manag 22:1625-1647

Yakowitz S (1982) Dynamic programming applications in water resources. Water Resour Res 18:673-696

Yazicigil H, Houck MH, Toebes GH (1983) Daily operation of a multipurpose reservoir system. Water Resour Res 19:1-13

Yeh WWG (1985) Reservoir management and operations models: a state-of-the-art review. Water Resour Res 21:1797-1818

Yeh CH, Labadie JW (1997) Multiobjective watershed-level planning of storm-water detention systems. J Water Resour Plan Manage ASCE 123:336-343 